\title{
Letters
}

\section{Research ethics}

SIR

The increasing awareness of the problems in the areas both of research ethics, and of the research ethics committees which have been created to safeguard research ethics, is evidenced in the symposium section of the last issue of the Fournal of Medical Ethics.

The desire for these problems to be solved, not least by local committees themselves, has meant that the proposal to create a national research ethics committee has been acclaimed somewhat too hastily. One of the main problems needing a solution is the great diversity of standards and practice between different local committees (1). A national committee, as Dr Macara acknowledges (2), would not be in a position to deal with this problem. This would leave the national committee with the functions of dealing with difficult scientific or ethical problems arising from particular research proposals and of assessing multicentre trials. It would also be high profile, which is an important point in light of the need for medical research to be seen to be ethical.

The danger is that with the advent of such a committee the assumption would be made that all problems of research ethics and research ethics committees would then be solved. In fact the most serious problem, because the most widespread, would remain - that of the extreme diversity of committees, with inadequacy of practice in some cases. The likelihood of this problem being addressed would then decrease, because we would all think that sufficient action had been taken already.

Some efforts are being made by different organisations to help members of local committees improve their practice. Some are offering training conferences (the Centre for Philosophy and Health Care at Swansea, University of Wales; the Centre of Law and
Medical Ethics, King's College, London, etc), another is creating education packages for lay members (the National Association of Community Health Councils) and another a newsletter for local committees (the Institute of Medical Ethics). There is no mandate requiring members to train themselves, however, and since most of the training courses cost quite a lot, funding as well as motivation is needed for members to get to them. My suspicion is that many health authorities are either unwilling or unable to provide the money that is required. There is a danger that only members of 'good' committees will attend, members who are already aware of the need to improve practice and maintain standards, or members of committees set up within drugs companies which have the cash available, while members of inadequate committees remain untouched. In any case, the sum of the activities in this area is patchy and diverse in itself, and so the problem of diversity of committees is unlikely to be solved only by these $a d$ hoc means.

Another proposal has been much less widely canvassed (significantly its two public advocates were ethics committee chairmen $(3,4)$ ) which is to create a national association of research ethics committees. The advantage of this proposal is that such a structure, properly set up and administered, would be able to meet all the functions described above. It could create ad hoc committees, rather like those mentioned by Professor Drury, to deal with multicentre trials and difficult cases, using its own network to involve the local committees concerned. It could, by means of a conditional membership, ensure a good minimum standard of practice, ie membership would depend upon agreement to meet certain guidelines such as those of the Royal College of Physicians. It could be an information centre for committees, publicising and distributing news, details of conferences, updated guidelines, etc. In time its maintenance of standards would mean that only those committees who were registered with the association would be recognised by the clinical community and the publishers of research papers. It would thereby provide reassurance to the general public that a consistently high standard of ethical scrutiny was being undertaken and respected.

'The debate', to quote Dr Macara, 'will surely go on'. I hope that this alternative proposal for a national association of research ethics committees will become a part of it.

\section{References}

(1) Gilbert C, Fulford K W M, Parker C. Diversity in the practice of district ethics committees. British medical journal 1989; 299: 14371439.

(2) Macara A W. Ethical review of multicentred trials. Fournal of medical ethics 1990; 16: 150-152.

(3) Madden A P. [Letter]. British medical journal 1990; 300: 607-608.

(4) Chairman of a local research ethics committee speaking at the conference of ethics committee chairmen at the Royal College of Physicians, 1990 Feb 9.

CLAIRE GILBERT FOSTER The Ian Ramsey Centre, St Cross College, Oxford OX1 $3 \mathrm{LZ}$.

\section{Informed consent}

SIR

Informed consent is based on the presentation of facts and alternatives to patients by their physician. It is often claimed that this presentation should be objective and unbiased. Paternalistic recommendations, reflecting the physician's preference and minimising other options are to be avoided. 
Informed consent itself can be viewed differently and considered to be in and of itself a therapeutic choice which carries with it a morbidity. In this light, it follows that we should go to the patient and inform him or her that there are two ways to make a decision. One way is for the physician to explain the facts in lay terms and ask the patient to make the decision. The second way to make a decision, in its extreme, is for the physician to act in a paternalistic way and make the decision on the patient's behalf.

Consider a hypothetical experiment in which newly diagnosed breast cancer patients were randomly assigned into two groups. In one group the choices of therapy would be presented in a neutral way and the patient would then select one option. In the second group the surgeon would make the selection for the patient with no discussion. Further suppose that after five years, a followup evaluation revealed a 15 per cent higher survival rate in the second group.

While such experiments are not commonly done, there is reason to suspect that the outcomes might, in fact, be different in the two groups.

It is of concern that the ideal of neutrally informed consent has been pursued by ethicists who appear to be making the same error that they accuse the physicians of, ie, knowing which type of decision-making is best for the patient in the absence of unbiased data.

LEWIS S SOLOMON, MD

121 Sotoyome Street, Suite 201

Santa Rosa, California 95405, USA

\section{Ethics in preventive medicine}

SIR

I enjoyed reading the recent article by Dr Skrabanek (1) about ethics (or lack of ethics) in preventive medicine. This is an issue of increasing concern to me.

Of particular importance in primary prevention is that, by definition, the participants in programmes are healthy. Unethical decisions will affect people who have been previously entirely or apparently healthy (2). There must be a systematic assessment of risks and benefits for each programme. The risks of adverse effects to individuals have to be balanced against the benefits to the community. It is essential that participants in preventive programmes are fully informed of these risks and benefits.

As well as the ethical dilemmas faced by preventive medicine practitioners, there are also dilemmas faced by participants in programmes. An important one, relevant to vaccination programmes for the prevention of communicable disease, is that noncompliers with vaccines will penalise others. Non-compliers reduce the level of herd immunity and may ultimately contribute to outbreaks of disease. This again emphasises the importance of risk-benefit calculations, and the effective communication of same to participants in programmes. Only then is it possible to make informed decisions.

I congratulate Dr Skrabanek on his article (1) and strongly support his suggestion of a forum to identify the ethical problems posed by preventive medicine and health promotion. There is an urgent need to bring the issues into focus.

\section{References}

(1) Skrabanek P. Why is preventive medicine exempted from ethical constraints? Fournal of medical ethics 1990; 16:187-190.

(2) Doxiadis S, ed. Ethical dilemmas in health promotion. Chichester: John Wiley and Sons, 1987.

ANTHONY G CAPON, MBBS BMedSC PhD FAFPHM Deputy Head,

Public Health and Epidemiology Unit, Menzies School of Health Research, PO Box 41096, Casuarina, Northern Territory 0811, Australia and Member,

Institutional Ethics Committee of the Royal Darwin Hospital and the Menzies School of Health Research 